\section{Hydrocephalus treated by compressive head wrapping}

Sir,

The recent report by Porter (1975) is stimulating and seems to attract attention. Everybody would agree that the currently used shunt procedures, ventriculoatrial or ventriculoperitoneal, are far from ideal for the reasons he gives. However, we wonder whether it is not precipitate at this stage to recommend the head wrapping method to paediatricians as a viable alternative to shunt dependency in treating neonatal hydrocephalus. It is a relatively new method, tried in a very limited number of children, and so far no long-term follow-up information is available.

Neonatal hydrocephalus is a symptom and not a nosological entity. It is not sufficiently clear from previous reports (Epstein, Hochwald, and Ransohoff, 1973; Porter, 1975) whether head wrapping is indiscriminately recommended for any neonate with moderate hydrocephalus, or whether it is intended as treatment in only those children with associated meningomyelocele. In trying to assess the value of this newly proposed method it is desirable to know as much as possible about the intracranial anatomy before starting treatment. A simple 'bubble' brow-up ventriculogram is not enough for this purpose. It might well be that certain 'types' of hydrocephalus (e.g. basal cistern block, aqueduct stenosis, Arnold-Chiari malformation, etc.) respond better or worse to head wrapping.

It is not easy to evaluate the results of this method of treatment by head circumference measurements since these can be quite misleading and may not reflect ventricular size. This problem can be overcome without the need for encephalography by newer methods (e.g. computerized axial tomography, ultrasound), but these, as a rule, are not yet freely accessible to most paediatricians. Children with repaired meningomyeloceles considered to have 'arrested' hydrocephalus (without shunt or without functioning shunt) have developed hydromyelia with deterioration in lower limb and bladder function in a significant number of cases (Hall, Campbell and Kalsbeck, 1975). The majority of these children have an associated Arnold-Chiari malformation. It seems to us to be possible, therefore, that by compressive head wrapping not only 'the pathways of (CSF) absorption have opened' (Porter, 1975) but the central spinal canal is kept open as well, thus contributing to hydromyelia formation with its possible consequences.

\section{E. BOLTSHAUSER and N. CAVANAGH Department of Neurology, Hospital for Sick Children, Great Ormond Street, London, WC1N 3JH.}

\section{REFERENCES}

Epstein, F., Hochwald, G. M., and Ransohoff, J. (1973). Neonatal hydrocephalus treated by compressive head wrapping. Lancet, $1,634$.

Hall, P. V., Campbell, R. L., and Kalsbeck, J. E. (1975). Meningomyelocele and progressive hydromyelia. Fournal of Neurosurgery, 43, 457.

Porter, F. N. (1975). Hydrocephalus treated by compressive head wrapping. Archives of Disease in Childhood, 50, 816.

\section{Dr. Porter replies as follows:}

I welcome the opportunity to reply to the points raised by Drs. Boltshauser and Cavanagh. Epstein, Hochwald, and Ransohoff (1973) have laid down specific criteria for the selection of cases for treatment by head wrapping, and I accept these. To save space in my short report I did not quote them, but merely referred to their paper; however, to avoid confusion I would like to reiterate their criteria here.

Each case should fulfil them all: (1) Progressive hydrocephalus with normal or only slightly increased intraventricular pressure. The pretreatment pressure in published cases has been $180-220 \mathrm{~mm} \mathrm{H}_{2} \mathrm{O}$ (Epstein et al., 1975). (2) Confirmation of the diagnosis by ventriculography. (3) Mild to moderate ventriculomegaly (cortical mantle $>1.5 \mathrm{~cm}$ ). (4) Good general medical condition. Within these criteria, the treatment has been used for cases of hydrocephalus with and without meningomyelocele.

I agree that a full series of ventriculographic views is desirable, and this was done in the case I reported, hence I was able to state occipital as well as anterior cerebral mantle thicknesses. I quoted brow-up measurements not to imply that a single view would suffice, but to allow comparison with Epstein et al. (1973).

It is because serial head circumference measurements may not reflect ventricular size that Epstein et al. (1973) supplemented these with repeated follow-up ventriculograms, and I used ultrasound (Porter, 1975). Epstein et al. (1975) now have access to computerized axial tomography (EMI scan) for the same purpose.

Nevertheless, head circumference measurements are widely used in the routine follow-up of cases treated with conventional shunts, and if they are good enough for that, they should be admissible evidence in head-wrapped cases too. Most hospitals in the U.K. large enough to support a paediatric service have ultrasound equipment as it is widely used to measure the fetal biparietal diameter during pregnancy. Its use in infancy to measure the anterior cerebral mantle is a skill which the average paediatrician could soon learn.

The possibility of the future development of hydromyelia in children whose hydrocephalus is treated with head wrapping remains a matter for speculation. Hall. Campbell, and Kalsbeck (1975) only reported 5 cases, 
of which none had received head wrapping, and 3 had been treated by shunt procedures in the neonatal period. In these 3 shunt failure was thought to have antedated the hydromyelia.

There is at present no evidence that head wrapping has caused any cases of hydromyelia. Even if it did develop in a few cases, it would be unlikely to produce symptoms for some years: the youngest patient reported by Hall et al. was aged 3 and the eldest 16 at the onset of symptoms. By then patients would be outside the age range at which ventriculoperitoneal shunt complication rates are maximal (Stark et al., 1974), so that a shunt for the few patients needing one might then be a satisfactory proposition. Like Epstein, I do not suggest that head wrapping is a panacea for hydrocephalus, but only that in cases fulfilling the selection criteria it may prove more satisfactory than shunt procedures.

F. N. PORTER Medical Paediatric Department, Western General Hospital, Crewe Road, Edinburgh EH4 $2 X U$.

REFERENCES

Epstein, F. J., Hochwald, G. M., Wald, A., and Ransohoff, J. (1975). Avoidance of shunt dependency in hydrocephalus. Developmental Medicine and Child Neurology, 17, Suppl. 35, 71.

Stark, G. D., Drummond, M. B., Poneprasert, S., and Robarts, F. H. (1974). Primary ventriculo-peritoneal shunts in treatment of hydrocephalus associated with myelomeningocele. Archives of Disease in Childhood, 49, 112.

\section{Usefulness of the xylose test for coeliac disease}

Sir,

We have read with interest the discussion in the Archives (1975, 50, 748) by Rolles et al., and Lamabadusuriya et al. following the communications of Lamabadusuriya, Packer, and Harries (1975) and Rolles, Anderson, and McNeish (1975).

During a $1 \frac{1}{2}$-year period in 1972-73 we performed 93 xylose tolerance tests on 75 children as a screening procedure (Ose and Fluge, 1974). 57 duodenal biopsies were also performed on 48 patients. Before biopsy, D-xylose $(0.5 \mathrm{~g} / \mathrm{kg})$ was given as a $5 \%$ solution, and capillary specimens were collected before, and at $\frac{1}{2}, 1$, and 2 hours after. Whenever possible a 5-hour urine collection was completed. Urine and blood xylose were measured using o-toluidine (Ose, 1973).

The 1-hour blood xylose value was maximal in most tests, and 12 of 79 children showed 1-hour values below $20 \mathrm{mg} / 100 \mathrm{ml}$. Of these 12 with reduced absorption of xylose, 4 patients had untreated coeliac disease, and 1 infant had cow's milk intolerance and a flat duodenal mucosa. In the remaining 7 cases there were 5 with enteritis, 1 with pneumonia, and 1 child with suspected coeliac disease but with normal histology on a normal diet. Thus an abnormal xylose test indicated glutenassociated mucosal changes in the small intestine in only 4 of 12 cases.

Introduction of gluten for a period of 1-3 months in 6 patients with proven coeliac disease resulted in a decrease of the mean 1-hour xylose value from 49-19 $\mathrm{mg} / 100 \mathrm{ml}$. The overall reduction was most pronounced 1 hour after loading (range $10-50 \mathrm{mg} / 100 \mathrm{ml}$ ). 3 of the 6 patients, however, had 1-hour values above $20 \mathrm{mg} /$ $100 \mathrm{ml}$, though in all 6 patients the mucosa had changed from normal to partial or subtotal villous atrophy. We concluded that during gluten challenge the test is only useful when the prechallenge value is known. Even so, a decrease in the 1 -hour value is not diagnostic of coeliac disease.

The xylose tolerance tests were grouped according to clinical symptoms and final diagnosis, but only untreated coeliac patients showed significantly reduced absorption. The test was of no use in evaluation of 16 patients with silent relapse on gluten-containing diet, as in older children with untreated coeliac disease (Visakorpi, 1972). Though all those patients had mucosal changes, the xylose absorption did not differ from the controls.

The results of the xylose tests were also compared on the basis of mucosal appearance on light microscopy. No differences could be shown between patients with normal duodenal mucosa and those with partial villous atrophy. The absorption was decreased only in patients with subtotal or total villous atrophy.

During the last 2 years 17 new patients with coeliac disease have been diagnosed. The xylose test was done in 14, and the mean 1-hour xylose concentration was $9 \mathrm{mg} / 100 \mathrm{ml}$ serum (range $1-24 \mathrm{mg} / 100 \mathrm{ml}$ ). Two patients aged 5 and 6 years both had a 1-hour value of $24 \mathrm{mg} / 100 \mathrm{ml}$-close to the mean $-2 \mathrm{SD}(22 \mathrm{mg} / 100$ $\mathrm{ml}$ ) in 15 controls aged 4-11 years-though in both biopsy showed subtotal villous atrophy. In a few cases where intestinal biopsy has been taken on account of reduced xylose absorption the biopsy has proved normal.

A 5-hour urine xylose test could only be completed in 59 of 79 patients as part of the diagnostic work up. The difficulties in obtaining accurately timed urine collections resulted in urine only from 1 of 4 untreated coeliac children during the years 1972-73. We agree that the urinary xylose test should be abandoned as a screening test in the paediatric population, but find that the blood xylose tolerance test is of value if one is aware of its limitations.

\section{LEIV OSE* and GJERMUND FLUGE, Department of Paediatrics, 5016 Haukeland Sykehus, University of Bergen, Norway.}

REFERENCES

Lamabadusuriya, S. P., Packer, S., and Harries, J. T. (1975). Limitations of xylose tolerance test as a screening procedure in childhood coeliac disease. Archives of Disease in Childhood, 50, 34.

Ose, L. (1973). D-xylose tolerance in malabsorption: method of determining D-xylose in serum and urine. Tidsskrift for Den Norske Legeforening, 93, 2103. 